\title{
First Rites-A Spiritual History Case Study
}

\author{
Alex Herbert Lion, DO, MPH
}

My patient was playing high school tennis when she noticed a painful bump on her right hand. She had heard about some players getting bone spurs, but the bump became bigger and more painful over the next few weeks. Soon it was marching band season, and she had trouble playing her trumpet. Her parents brought her to a pediatrician, who noted her symptoms of back pain, trouble breathing, and the hand mass. A chest radiographic image was taken, and she was found to have pleural effusions, fluid accumulating between the lungs and a saran wrap-like covering for the lungs (the pleura). A chest computed tomography scan was done, and the pediatrician then sent the patient to my pediatric oncology clinic.

I looked at the patient, who could not walk without getting short of breath, and her chest computed tomography results. The pleural effusion was causing her trouble breathing. In addition, there were vertebral fractures and a chest wall mass, all concerning for a malignant condition spread from the mass on her hand. I admitted her to the hospital, where she had a biopsy performed and a chest tube placed to drain the fluid. I sat with the family at her bedside for part of the waiting. The patient and I had several things in common. We both watched Doctor Who. We talked about some of our favorite episodes and debated who the best Doctor was (she liked David Tennant the best). In addition, Amber wanted to go to medical school.

This is the author's manuscript of the work published in final form as:

Lion, A. H. (2020). First Rites-A Spiritual History Case Study. JAMA Oncology, 6(4), 475. https://doi.org/10.1001/jamaoncol.2019.5980 
"I'm taking this experience as learning for when I'm a doctor someday," she said, not yet knowing what kind of prognosis she might have. She was excited to see her computed tomographic scan and asked me if she could see her pathology slides. I made a note to talk to the pathologist.

Although I was early in my fellowship, I knew that cancer is more than pathology. In addition, I had been influenced by a movement in medicine that encourages clinicians to ask deeper questions of values and narrative. I had developed a rapport with this patient, and I felt like I could take the plunge and ask the harder questions.

"What gives you support when you are faced with hard things?" I asked her. "Are there any religious or spiritual needs that we can support you in as you are going through this?" The patient's mother was the first to answer. "I believe the body is a shell for the spirit," she said. "We are very spiritual." She was a massage therapist who had a special interest in manual therapies using so-called energy healing. I spoke some words of respect for their values. It was not an exhaustive conversation, but it had opened a space. My patient said, "I feel like you were meant to be my doctor." I smiled and left the room.

Two days later, the pathologist finalized his report: the diagnosis was metastatic alveolar rhabdomyosarcoma-a cancer that at this stage was nearly incurable. Without any treatment, though, the pleural effusions would reaccumulate and her life would be shortened even further. After discussing the options, my patient and her family chose standard medical therapy. Chemotherapy and radiation represented a break from the traditions of some of their friends. The direct adverse effect of chemotherapy and radiation would be a decreased energy in the body, if only temporarily, at least.

"Do you know of any reiki practitioners in the area?" her mother asked after she signed the treatment consent. "Let me check," I said before leaving the room. After I googled reiki and asked around, I discovered that the palliative care team had someone who knew reiki. Reiki was one of the early entry points for the relationship that would build between my patient, her mother, and the palliative care 
team. They also welcomed the chaplain, who would hold the patient's infant sister while they sat and talked.

My patient weathered nearly a year of nausea and tiredness by spending time in a tank after treatments. These tanks were sensory-deprivation chambers in which she would relax and let go of anxiety. As time passed, the family also sought out and began to attend a traditional faith-based congregation. In our visits, it was common for them to share updates in their spiritual journey with me, because I had made my office a safe place for them to talk about these things that were clearly very important to them. At last, 42 weeks had passed, and the treatment protocol was completed.

It was mere weeks after treatment ended that I received a message: "She is having trouble breathing, and it feels like the first time." I was out of state, so I made 2 phone calls. In the first, the patient's mother shared with me the things her family was praying for. In the second, I spoke to the oncology team and made a plan that could be carried out until my out-of-state trip was completed.

By the time I arrived in town, we had proof from the pathology department that the patient had relapsed. The pleural effusions had started to reaccumulate. I came to sit again at her bedside. The silence was deeper and longer. My patient talked about her frustration. She wanted to go to medical school and make her mark. "You've made a mark," I said. "You've made a mark on me. You and your family have inspired me by your example of spirituality. I think it would inspire others, if you wanted me to share it with them." She nodded her head yes. "Please do so," her mother said.

"I don't know how you do this job," her mother told me, breaking a prolonged silence. It was surely a rhetorical statement, but I found myself talking about my morning routine. Before meeting children and families struggling with cancer, I sing on the way to work. Some songs specifically reminded me of certain patients. There was one that came out while I was out of state, and I had been singing it since I 
had received the message from her. "It would be nice to hear that song," she said. My patient smiled and nodded in agreement.

"Will your boyfriend be jealous if I hold your hand while I sing?" I asked. That brought on a small laugh and a cough. It had been many years since I had sung for such an important audience; higher education does not always support preservation of creativity and art. Those 5 minutes of song at her bedside were moments in which what is most important could not be crowded out by what is merely urgent. It was a song that spoke to life, death, and what comes next. Once the song had completed, the mother remarked, "It's nice to know that there's more to oncology than chemotherapy." Her daughter smiled that brave smile of hers. "I don't feel as afraid," she said. We shared a teary-eyed gaze, and I let her hand go.

More than a year after my patient died, I received a new message from her mother. "I dreamt about her the other night. She was looking so healthy and vibrant. I was debating whether or not I should schedule an appointment for her to have a check-up with you since she looked so well. My thoughts were, 'It's been so long since her last chemo treatment, they didn't predict that she'd be doing so well, I wonder what they'll say?!' When I checked in with her she was packing up her room, she said she didn't need it any more. When I checked into her room again, she was gone, it was all cleaned up. She left me a note on the wall. I don't remember all of it, but the gist of it was, she went on before us, she was happy and healthy and that she would see us soon."

There are these patients I treat and provide care for, whose values I am invited to integrate into the practice of medicine for them. Then there are these moments when I stand in awe of the stories of my patients, as if the more I meditate on their stories, the more my calling in health care finds resonance. The day I chose to go deeper-to listen to these sacred narratives and integrate the spirituality of patients - was like an initiation, the beginning of something new. These were the first rites. I am a better 
human for the work I do, and my work is continually being renewed in meaning and purpose not because of how my story influences patients but because of how their stories continue to live in me.

Corresponding Author: Alex Herbert Lion, DO, MPH, Riley Hospital for Children at Indiana University Health, 705 Riley Hospital Drive, RI 4340, Indianapolis, IN 46202

Conflict of Interest Disclosures: None reported.

Additional Contributions: We thank the patient's family for granting permission to publish this information. 